\title{
Further Evidence for Carotenoids Engaged in a Metastable State in Photosynthesis
}

\author{
H.-E. BuCHWALD and $\mathrm{CH}$. WOLFF \\ Max-Volmer-Institut, I. Institut für Physikalische Chemie, Technische Universität Berlin
}

(Z. Naturforsch. 26 b, 51-53 [1971] ; received 3 September 1970)

\begin{abstract}
During photosynthesis a metastable state is formed by superfluous excitation energy. Only carotenoids are responsible for the metastable state. Especially no chlorophyll-a is involved in this state. This result was obtained by using the repetitive ultra-short-flash technique in combination with the high frequency modulated measuring light technique.
\end{abstract}

During photosynthesis a metastable state with a half life of $\sim 3 \mu$ s has been observed which probably represents a valve for superfluous excitation energy ${ }^{1}$.

The difference spectrum caused by the formation of this state shows three pronounced negative peaks in the blue spectral range (at 430,460 and $490 \mathrm{~nm}$ ). Therefore probably a carotenoid is involved. Because of the negative peak at $430 \mathrm{~nm}$ the participation of chlorophyll-a could not be excluded. But in this case there must occur additionally absorption changes in the red spectral range between 660 and $705 \mathrm{~nm}$ where chlorophyll-a in vivo has its second absorption band but not the carotenoids.

Measurement of fast and small absorption changes within microseconds can, however, not be carried out by the normal ultra-short-flash photometry apparatus ${ }^{1}$ in the red spectral range because of the $\cong 10^{4}$ times larger chlorophyll fluorescence at the same wavelengths. This fluorescence can, however, be eliminated from interference with absorption changes by a special apparatus allowing time resolution of about $1 \mu \mathrm{s}^{2}$. With this apparatus we succeeded in extending the difference spectrum in question into the red region. No absorption changes of $\sim 3 \mu$ s life time take place in the red. Therefore only carotenoids are responsible for the observed metastable state. This has already been reported in ${ }^{1}$. The experimental documents and details on these measurements in the red region are presented in this paper.

\section{Methods and Material}

Formation and deactivation of the metastable state in spinach chloroplasts were recorded by the repetitive flash photometry with high frequency modulated detecting light ${ }^{2}$. This apparatus was capable to separate completely fast absorption changes of $\Delta I / I=5 \cdot 10^{-5}$ from $5 \cdot 10^{4}$ times larger fluorescence signals.
The excitation of photosynthesis was performed by ultra short flashes ${ }^{1}$. With a multi-channel averager (Fabri-Tek Model 1072) the extremely small signal-tonoise ratio was enhanced by the factor 200 .

Besause of the limited time resolution of the averager $(1 \mu \mathrm{s})$ it was suitable to use chloroplasts in glycerol. In such a suspension the life time of the metastable state is two times larger $\left(t_{1 / 2} \cong 7 \mu \mathrm{s}\right)$ than in an air-saturated aqueous suspension $\left(t_{1 / 2} \cong 3 \mu \mathrm{s}\right){ }^{1}$.

The spinach chloroplasts were prepared as described in ${ }^{1}$. For the measurements they were suspended in glycerol from Merck (redistilled p.a., density 1,23).

\section{Results}

Firstly, measurements were performed at the wavelengths 430 and $515 \mathrm{~nm}$ (see Fig. 1) at which the formation and deactivation of the metastable state are indicated by characteristic absorption changes ${ }^{1}$. Fig. 2 shows that these absorption changes of chloroplasts suspended in glycerol $\left(t_{1 / 2} \cong 7 \mu \mathrm{s}\right)$ give the same amplitude ratio as the absorption changes of chloroplasts in an air-saturated aqueous suspension $\left(t_{1 / 2} \cong 3 \mu \mathrm{s}\right)$.

In the red spectral range between 660 and $705 \mathrm{~nm}$ where chlorophyll-a in vivo absorbs, however, no absorption changes with a half life of $7 \mu$ s could be observed (see Figs. 1 and 2). In this range there are only absorption changes observable with slow decay times $\gg 7 \mu$ s. These absorption changes have already been attributed to the photo-

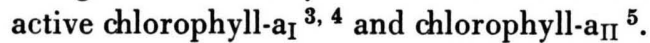

Reprints request to Dr. CH. WolfF, Max-Volmer-Institut, I. Institut f. Physikal. Chemie, D-1000 Berlin 12, Straße des 17. Juni 135 .

1 Ch. WolfF and H. T. Witt, Z. Naturforsch. 24 b, 1031 [1969] ; CH. WolfF, Thesis, Berlin 1969.

2 H.-E. Buchwald and H. RüPPEL, Nature [London] 220, 57 [1968] ; H.-E. Buchwald, Thesis, Berlin 1969.

3 B. KoK, Acta botan. neerl. 6, 316 [1957].

4 B. Rumberg and H. T. Witt, Z. Naturforsch. 19 b, 693 [1964].

5 G. Döring, G. Renger, J. Vater, and H. T. Witt, Z. Naturforsch. 24 b, 1139 [1969]. 


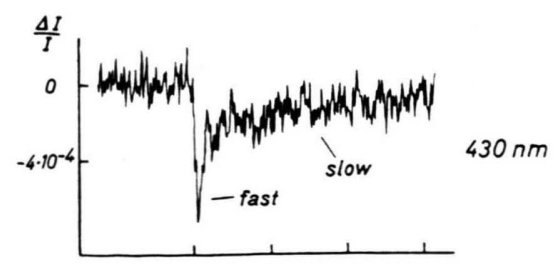

are at least as large as the blue bands we estimate the possible participation of chlorophyll-a in the $430 \mathrm{~nm}$ band as being smaller than $20 \%$ of the total amplitude.

\section{Discussion}

The negative pepaks at 430,460 and $490 \mathrm{~nm}$ (see
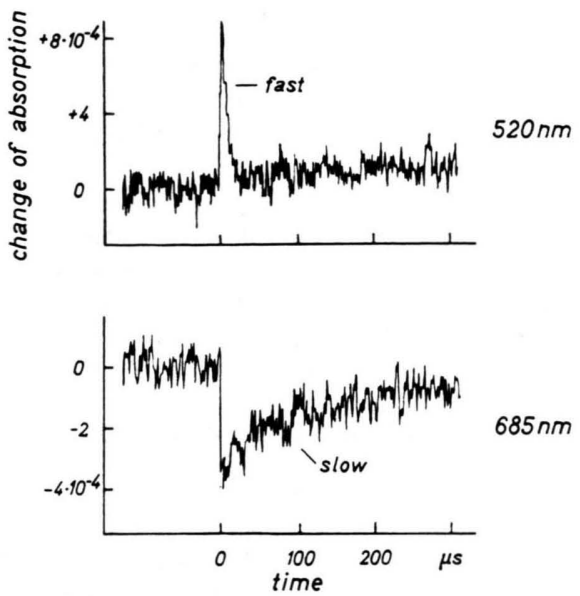

Fig. 1. Time course of the absorption changes at $\lambda=430,520$ and $685 \mathrm{~nm}$ in a suspension of spinach chloroplasts in glycerol. Chlorophyll content: $10^{-6} \mathrm{M}$. Water content: about $5 \cdot 10^{-2} \mathrm{M}$. Temperature: $20^{\circ} \mathrm{C}$. Optical path: $78 \mathrm{~mm}$. $\lambda>$ $610 \mathrm{~nm}(2 \mathrm{~mm} \mathrm{RG} 1)$, duration $4 \cdot 10^{-7} \mathrm{~s}$, repetitive ultrashort-flash technique, frequency $10 \mathrm{~Hz}, 41.160$ flashes were fired per measurement. Measuring light: interference filters $\lambda=430 \mathrm{~nm}(\Delta \lambda=20 \mathrm{~nm}), 520 \mathrm{~nm}(15 \mathrm{~nm})$ resp. $685 \mathrm{~nm}(13$ $\mathrm{nm})$. Electrical bandwidth : $1 \mathrm{MHz}$.

Fig. 2 shows that in the whole range 660 to $705 \mathrm{~nm}$ possible absorption changes with $t_{1 / 2} \cong 7 \mu \mathrm{s}$ are smaller than $20 \%$ of the blue peak at $430 \mathrm{~nm}$. Because the red difference bands of other chlorophyll-a-reactions (e. g. triplet formation in vitro ${ }^{6}$ )

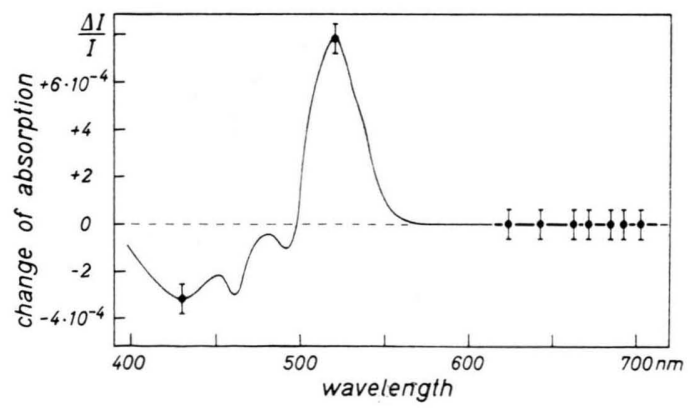

Fig. 2. Measuring points: Fast absorption changes indicating the metastable state in a suspension of spinach chloroplasts in glycerol $\left(t_{1 / 2} \cong 7 \mu \mathrm{s}\right)$. Measuring light: interference filters, half width: about $15 \mathrm{~nm}$. For further details see Fig. 1 . Solid line: Spectrum of the absorption changes indicating the metastable state in an air-saturated aqueous suspension of spinach chloroplasts $(t 1 / 2 \cong 3 \mu \mathrm{s})^{1}$. spectrum Fig. 2) could be caused by the reaction of 1. chlorophyll-a $(430 \mathrm{~nm}), 2$. chlorophyll-b $(460 \mathrm{~nm}), 3$. carotenoids (all three wavelengths) and 4. flavins (all three wavelengths).

Chlorophyll-b is out of the question because the metastable state is formed also in algae containing no chlorophyll-b ${ }^{7}$.

Flavins in vivo have an absorption spectrum with three peaks (respectively shoulders) between 400 and $500 \mathrm{~nm}^{8}$. However, the excited metastable state of flavins has no absorption band at wavelengths above $500 \mathrm{~nm}^{9}$. Therefore the flavins are out of the question, too.

Only chlorophyll-a (Chl) and carotenoids (Car) are left for discussion. Our results show that chlorophyll-a forms if at all maximal $20 \%$ of the amplitude at $430 \mathrm{~nm}$, that means

$$
\frac{\Delta A_{\mathrm{Chl}}}{\Delta A_{\mathrm{Car}}}<\frac{1}{4} .
$$

With the carotenoid absorption coefficient in vitro ${ }^{13}$ and the change of the chlorophyll absorption coefficient during triplet formation in vitro ${ }^{6}$ at $430 \mathrm{~nm}$ it follows a concentration ratio which is accidental the same as the ratio of the absorption changes:

$$
\frac{C_{\mathrm{Chl}}}{C_{\mathrm{Car}}}<\frac{1}{4} \text {. }
$$

Thus the concentration of chlorophyll-a which, if at all, is converted to the metastable state must be smaller than $25 \%$ of that of the carotenoids.

6 R. Livingston, in: Handbuch der Pflanzenphysiologie, Vol. V/1, p. 830, Ed. W. RuHland et al., Springer-Verlag, Berlin-Göttingen-Heidelberg 1960; K. SEIFERT and H. T. WITT, Naturwissenschaften 55, 222 [1968].

7 R. Moraw and H. T. Witt, Z. physik. Chem. NF 29, 1 [1961].

8 M. Shin, K. Tagawa, and D. I. Arnon, Biochem. Z. 338 , 84 [1963].

9 A. KNowles and E. M. F. Roe, Photochem. Photobiol. 7, 421 [1968].

10 K. Witt and $C_{H}$. Wolff, Z. Naturforsch. 25 b, 387 [1970].

11 T. H. Ji, J. L. Hess, and A. A. Benson, Biochim. biophysica Acta [Amsterdam] 150, 676 [1968].

12 K. Yamashita, K. Konishi, M. Itoh, and K. Shibata, Biochim. biophysica Acta [Amsterdam] 172, 511 [1969]. 13 P. Karrer and E. Jucker, Carotinoide, Birkhäuser, Basel 1948. 
As the excitation of the metastable state is possible even with red light only $(\lambda>610 \mathrm{~nm})^{1}$ the metastable state is undoubtedly formed via chlorophyll-a absorption (bulk absorption) :

$$
\begin{aligned}
\mathrm{Chl} & \stackrel{h v}{\rightarrow} \mathrm{Chl}^{*}, \\
\mathrm{Chl}^{*}+\mathrm{Car} & \rightarrow \text { metastable state } .
\end{aligned}
$$

If the chlorophyll-a is involved in the metastable state itself than only a complex between chlorophyll-a and carotenoids would be possible because of the uniform kinetics of deactivation ${ }^{1}$ :

$$
\mathrm{Chl}^{*}+\mathrm{Car} \rightarrow(\mathrm{Chl}-\mathrm{Car}) \bullet \mathrm{Chl}+\mathrm{Car} .+
$$

In this case, however, it would be expected a concentration ratio $C_{\mathrm{Chl}} / C_{\mathrm{Car}}=1$.

As this is contrary to the above estimation it can be followed now that there is no chlorophyll-a at all involved in the metastable state itself. Only the excitation energy is transferred from chlorophyll-a to carotenoids:

$$
\begin{array}{cl}
\mathrm{Chl}^{*}+\mathrm{Car} \rightarrow \mathrm{Chl}+\mathrm{Car}^{\bullet} t_{1 / 2}<25 \mathrm{~ns}^{10} . \\
\mathrm{Car}^{\bullet} \rightarrow \mathrm{Car} & t_{1 / 2} \cong 7 \mu \mathrm{s} \\
& \text { (without deactiva- } \\
& \text { tion by } \mathrm{O}_{2} \text { ). }
\end{array}
$$

Our conclusion that only carotenoids participate in the metastable state is supported additionally by the following facts (see also l.c. ${ }^{1}$ ) :

\footnotetext{
+ Abbreviations: $\mathrm{Chl}, \mathrm{Chl}^{*}=$ chlorophyll-a in its ground state and excited state respectively. Car, Car $\bullet=$ carotenoid in its ground state and metastable state respectively. (ChlCar) $\bullet=$ metastable complex consisting of chlorophyll-a and carotenoid.
}

1. The negative difference bands (see Fig. 2) have their maximum just at those wavelengths where the carotenoids in vivo absorb.

Extracting ${ }^{11}$ and photo-bleaching of chloroplasts $^{12}$ result in the fact that two of the carotenoid absorption maxima in vivo are at 460 and $490 \mathrm{~nm}$ and that the third maximum is not located at wavelengths above $500 \mathrm{~nm}$. This third maximum is probably at $430 \mathrm{~nm}$, but it could not be resolved because of the strong chlorophyll-absorption.

2. The distance of $30 \mathrm{~nm}$ between the negative difference bands corresponds exactly to the vibrational structure in the absorption spectrum of the carotenoids ${ }^{\mathbf{1 3}}$.

3. The positive absorption change at $520 \mathrm{~nm}$ (Fig. 2) reflects the metastable state absorption of carotenoids as it was shown by experiments in vitro ${ }^{14}$.

The metastable state is formed in different species of algae indicated by very similar difference spectra ${ }^{7}$. These algae have totally different compositions of carotenoids $^{15}$. Therefore probably several types of carotenoids are involved in the formation of the metastable state.

The stimulation of this work by Professor H. T. WITT is gratefully acknowledged.

14 M. Chessin, R. Livingston, and T. G. Truscott, Trans. Faraday Soc. 62, 1519 [1966].

15 T. W. Goodwin, in: Chemistry and Biochemistry of Plant Pigments, p. 132, Ed. T. W. Goodwin, Academic Press, London/New York 1965. 